The following pages constitute the final, accepted and revised manuscript of the article:

Werntoft, Elisabet and Edberg, Anna-Karin and Rooke, Liselotte and Hermerén, Göran and Elmståhl, Sölve and Hallberg, Ingalill Rahm

"Older people's views of prioritization in health care.

The applicability of an interview study"

J Clin Nurs. 2005 Sep;14(8B):64-74.

Publisher: Blackwell

Use of alternative location to go to the published version of the article requires journal subscription.

Alternative location: http://dx.doi.org/10.1111/j.1365-2702.2005.01278.x 


\section{Older people's views of prioritisation in health care. The applicability of an interview study.}

Werntoft E, RNT, PhM ${ }^{1}$, Edberg A-K, RN, PhD, Assoc Proffessor ${ }^{1}$, Rooke L, RNT, Assoc Professor $^{2}$, Hermerén G, PhD, Professor ${ }^{3}$, Elmståhl S, MD, Professor ${ }^{4}$, \& Hallberg IR, RNT, $\mathrm{PhD}$, Professor ${ }^{1}$.

${ }^{1}$ Department of Nursing, Lund University, P.O.Box. 157, SE-221 00 Lund, Sweden.

E-mail: elisabet.werntoft@omv.lu.se, Tel: +46-46-2221840, Fax: +46-46-2221846

E-mail: anna-karin.edberg@omv.lu.se, Tel: +46-46-2221980, Fax: +46-46-2221935

E-mail: ingalill.rahm_hallberg@omv.lu.se, Tel: +46-46-2221932. Fax: +46-46-2221808

${ }^{2}$ Regional Director’s Office, R\&D. Region Skåne, JA Hedlunds väg, SE-291 89 Kristianstad, Sweden. E-mail: liselotte.rooke@skane.se

Tel: +46-44-133000. Fax: +46-44-133489

${ }^{3}$ Department of Medical Ethics, Lund University, SE-221 00 Lund, Sweden.

E-mail: goran.hermeren@svet.lu.se, Tel: +46-46-2221280. Fax: +46-46-2221285.

${ }^{4}$ Department of Community Medicine, Lund University, Malmö University Hospital, SE-205

02 Lund, Sweden. E-mail: solve.elmstahl@smi.mas.lu.se

Tel: +46-40-331973. Fax: +46-40-336215.

\section{Corresponding author}

Elisabet Werntoft

Department of Nursing

Lund University

P.O.Box. 157

SE-221 00 Lund

Sweden.

E-mail: elisabet.werntoft@omv.lu.se

Tel: +46-46-2221840

Fax: +46-46-2221935 


\title{
Older people's views of prioritisation in health care. The applicability of an interview study.
}

\begin{abstract}
Old age has been stated as a criterion for prioritisation in health care, although older people are seldom asked for their opinions. The aim of this pilot study was to investigate the applicability of a questionnaire as a base for an interview study to explore older people's experiences and views of prioritisation in health care. Design - Descriptive, with a qualitative and quantitative approach. Methods - Fifty-four persons, 32 women and 22 men (aged 60-93) were asked to participate in a structured, tape-recorded interview covering their experience and views of the priorities applied in health care. Results - The questions in the interview manual appeared to be applicable for collecting data concerning views of prioritisation, but the analysis revealed that certain questions, particularly on economic matters, were missing. The procedure, a personal structured interview had advantages, for example, in capturing the respondents' reflections on the questions. The respondents emphasised the equal value of all human beings and that age is not a basis for prioritisation within health care. The respondents also showed an unwillingness to precede anyone in rank. Implications - The questions used proved to be adequate but to be really complete further questions need to be added. This pilot study indicates that older people's views on priorities in health care differ from those expressed by the younger population. The study therefore needs to be replicated in a larger sample to be fully able to understand older people's views of prioritisation, which will require exploring gender and age differences as well as other aspects that may explain variations.
\end{abstract}

Key Words: Interview, Health care, Older people, Prioritisation, Questionnaire, View 


\section{INTRODUCTION}

In Sweden, people aged 65 and above account for almost one fifth of the entire population (SCB, 2003). The increasing age of the population, not only in Sweden but globally, is leading to people living a greater number of healthy years, but also to an increased risk of illness, which increases the needs for health care (WHO, 2000). This implies that the older population is at a high risk of being affected by decisions concerning prioritisation in health care.

Prioritisation means opting for one thing and discarding or postponing another. There are two options; one the focus on a choice between medical measures guided by considerations of the patient's need while the other focus is on resource constraints. Prioritisation due to resource constraints, for example, withdrawal of free medication, poses difficult ethical problems and questions of general interest (James, 1999) (UK). Prioritisation in health care has always been practised. Some sectors and patients have been given priority while others have been set aside, often not deliberately. According to the Swedish Parliamentary Priority Commission (SOU, 1995), this has not been made explicit and the reasons have not been transparent. Generally old age has been stated as a criterion for prioritisation in health care provision and treatment. A study made by Ryynanen (1997) (FIN) indicated that increasing patient age reduces a doctors' willingness to refer them for surgery, even though there are no purely medical contradictions, yet older people have seldom been asked about their opinions.

Several efforts to handle the use of prioritisation have been done in different countries. The emergence of explicit prioritisation is exemplified by experience from Oregon, USA, New Zealand, the Netherlands, the UK, Norway, Finland and Sweden. In all of these countries, prioritisation is high on the health policy agenda as publicly financed health care has come under review (Ham, 1997) (UK). The Norwegian priority setting report in turn, influenced the work of the Swedish Parliamentary Priorities Commission (Calltorp, 1999) (SWE), stating that no account should be taken of age when allocating resources within the health care system (SOU, 1995). The main result of the work of the Swedish Parliamentary Priority Commission is based on three ethical principles. (a) The principle of human dignity; human dignity is not geared to people's personal qualities or functions in the community, such as ability, social status, income etc., but to their very existence. (b) The principle of need and solidarity; giving most of the resources of care to those who are most in need and devoting special consideration to the needs of the weakest, for example, children, people with 
dementia, and others who have difficulty in communicating with others. (c) The costefficiency principle; one should aim for a reasonable relation between cost and effect measured in terms of improved health and enhanced quality of life. The principle of human dignity is supposed to override the principle of need and solidarity. Lowest rank is given to the cost-efficiency principle (SOU, 1995). Factors, such as the patient's age, are not mentioned in the report as being a criterion in prioritisation.

Although the Swedish Parliamentary Priority Commission did not recommend age as a criterion, one study on view of prioritisation, performed in a Swedish context, reported old age as a factor that they wanted to use in prioritisation (Johannesson \& Johansson, 1996) (SWE). The respondents, who were randomly selected, were asked whether they consider that life saving measures shall be given equally to all, regardless of age. The study showed that a majority favoured treatment for younger rather than older people. On average, people were willing to sacrifice five 50-year-olds or thirty-five 70-year-olds to save one 30 -year-old person (Johannesson \& Johansson, 1996) (SWE). That study and most other studies concerning people’s view of prioritisation, for example Bowling (1996)(UK), Myllykangas et al. (1996)(FIN), Myllykangas et al. (1997)(FIN) and Ryynanen et al. (2000) (FIN), have samples in which older people are sparsely represented or not represented at all. For instance, among the 1000 randomly selected adults who were asked about life-saving treatment with regard to age, in the study by Johannesson \& Johansson (1996) (SWE), the youngest persons were 15 years old, and the mean age was 46.6 (SD 18.5). Thus the majority of the sample was under 65 years of age and could be considered to be low consumers of health care. It might be difficult for younger people to imagine life being old and unhealthy, while older people have a life span perspective to relate to. Older people were oversampled in order to allow more precise comparisons of attitudes by age cohort in an American study (Zweibel et al., 1993). The authors asked whether the respondents agreed or disagreed with the statement that "lifeextending medical care should be withheld from older people to save money to help pay for the medical care of younger people”. Two thirds disagreed (68\%), but older respondents tended to be more likely than younger respondents to favour the policy (Zweibel et al., 1993) (USA). Mossialos \& King (1999) (UK) conducted a review of research concerning priorities and concluded that age-based prioritisation may stimulate inequality as the financially welloff older people will seek private health care services, while the poor older people may be forced to do without it. Because women have a longer life expectancy than men, prioritisation based on age can also be seen as discriminating against women (Bell, 1989) (USA). As many 
older people are in a worse situation economically than the younger population, their view of how to finance the increasing health care costs is important.

Studies have shown that the view of prioritisation is also marked by moral values. The results reported by Bowling (1996) (UK) resembled those of earlier surveys, where the lowest priority for treatment was given to "treatment for infertility" and "treatment for people aged 75 and over with life-threatening illness”. There also seemed to be public support for the view that people with self-inflicted conditions should receive lower priority for care. The result was based on interviews of a random sample of 2005 persons aged 16 years and over that was similar to the population as a whole, i.e. $49 \%$ were aged $16-44$, 31\% were $45-65$ and $20 \%$ were over 65. Thus the general public seemed to not only have age as a criterion for prioritisation in health care but also to have moral values when considering health service priority.

Studies concerning older people's views of prioritisation in health care have mainly been based on questionnaire surveys. The majority of the studies to be found concerning prioritisation in health care have used questionnaires with fixed response alternatives or statements to consider (Kinnunen et al., 1998, Myllykangas et al., 1996, Ryynanen et al., 1999) (FIN). The questionnaires have usually been mailed to the respondents and the response rate has been low, less than $60 \%$. The authors in those studies argued that questions about attitudes sometimes are difficult to answer, which could be the reason for the low response rates. Some respondents also reported that they felt anxious when answering the questionnaire (Ryynanen et al., 1999) (FIN). The advantage of questionnaire surveys, structured or systematic means of data collection, is that they allow information to be collected from a large sample of respondents and that the relations between variables can be examined (Jordan et al., 1998) (UK). Since questions about prioritisation are known to cause inconvenience to some respondents, a personal interview with structured questions may be preferable.

\footnotetext{
Aim

The aim of this pilot study was to investigate the applicability of a questionnaire as a base for an interview study to explore older people's experiences and views of prioritisation in health care.
} 


\section{MATERIAL AND METHOD}

The feasibility of a study is determined by, among other things, the availability of subjects, facilities and equipment; the adequacy of the data collection; and the study's ethical considerations. If structured interviews are used, it is important to know whether respondents understand the questions and directions and if they find any question objectionable. The interview manual has to cover the relevant areas, have the scope to reveal variation in the answers and be suitable for the people in the study group (Burns \& Grove, 2001, Polit \& Beck, 2004). Data was collected in connection with a larger prospective longitudinal cohort study, the GAS project (Good Ageing in Skane) that is currently in progress in southern Sweden, and which involves a representative panel of about 2900 older people from five municipalities (Lagergren et al., 2004). The GAS project is a part of the Swedish National study on Aging and Care (SNAC) a large, national, longitudinal study, initiated by the Swedish Ministry of Health and Social Affairs. In the GAS project a random sample is chosen from 9 age group cohorts between 60 and 93 years using the Total Population Register, Statistics, Sweden. The participants are invited to participate by letter and the data collection involves demographic data, living conditions, education, socio-economic conditions, social network and support, a medical examination and cognitive tests. Before inclusion in the study, written informed consent for participation in the study was obtained from the participants. The Ethics Committee of Lund University (LU 650-00) approved the study.

\section{Sample}

For this pilot study, all those who were included in the GAS project during a three-month period were asked consecutively to participate in an additional interview. The exclusion criterion for the study was language difficulties and for the interview cognitive decline. Six persons had to be excluded from participation in the study due to cognitive decline; no one refused to participate. In all, 54 persons, 32 women and 22 men, aged 60 to 93 years participated in the study. The median age was 72 years $\left(q_{1}-q_{3}, 65-83\right.$ years).

\section{Data collection}

Lewis and Cuevas (1996) stated that a researcher may use a self-constructed test if there are no acceptable instruments available. The theoretical rationale upon which item selection is based could be one attempt to support validity and so also revisions made as a result of a pilot study. As no questionnaires, suitable for older people, were found in the literature, a new questionnaire was constructed. The construction of the questionnaire was based on the three 
ethical principles the principle of human dignity, the principle of need and solidarity and the cost-efficiency principle, and on questions used in other studies that seemed valid in a Swedish context and/or covered the ethical principles. In all, four questions were replicated from previous studies, one question from Nord et al. (1996) concerning priorities in relation to age (question no. 3), and three questions from Mossialos \& King (1999), one concerning who should decide on priorities (question no. 6), one concerning how the increasing health care costs should be financed (question no. 8), and one asking about methods for selecting between patients (question no. 7). The latter question was modified from the original by changing the alternative "the decision is made by following the rules of the hospital, whatever they may be” to the alternative "the patients' age”. The remaining questions (questions no. 1, 2, 4 and 5) were constructed for this study to cover all three ethical principles. The questionnaire had one open-ended question, asking the respondents to describe their own views on and experience of prioritisation in health care, and seven structured questions with from four up to seven response alternatives to choose between. For further description see Table 1 and 2 . As only separate questions were selected from other questionnaires information on validity and reliability could not be obtained. The questions were discussed with a panel representing different professions, such as nurses, physicians and teachers. The main purpose of these discussions was to improve face validity.

Structured interviews based on the questionnaire were carried out in connection with the medical examination in the GAS project by the first author. The respondents were supported to narrate their apprehension in relation to the questions asked. The rationale for this procedure was previous reports from the literature indicating a need for the respondents to explain their standpoints in relation to each question, to avoid discomfort on the part of the respondents (Ryynanen et al., 1999). The first author sat next to the participant, read the questions and the response alternatives and filled in the answers. The 54 respondents reflected on and gave comments on the way the questions were constructed and on the content. All interviews were tape-recorded and lasted for about 30 minutes, with a variation between 10 and 55 minutes. The large variation in length was explained by the fact that some respondents made very little comment or did not discuss the questions at length, while others did.

\section{Analysis}

The questions with fixed response alternatives were analysed using descriptive statistics. 
Statistical data analysis was performed by using the Statistical Package for Social Sciences (SPSS; 11.5). The tape-recorded responses on the respondent's reflections about and experiences of priorities in health care, as well as their statements in relation to all questions were transcribed verbatim and thereafter analysed using manifest content analysis. Manifest content analysis focuses on the surface structure in the text while latent content analysis focuses on the meaning of the text (Berg, 2001). The first (EW) and second author (AKE) read the text, independently of each other and compared and discussed the text in relation to the aim and to each question. The texts were thereafter split into meaning units that appeared to share the same content and were sorted into categories inspired by the first reading. The statements in each category were thereafter analysed critically, read and compared, to identify sub-categories. The first and second authors again reflected on and discussed the findings taking the research question and their pre-understanding into account and finally discussed the categorisation with the last author (IRH), after which a final model was decided upon.

\section{RESULTS}

\section{The applicability of the questionnaire}

The respondents' reflections on the construction and content of the questions were mainly positive, for example they said that the questions were easy to understand and were relevant to the topic. The questions seemed to be comprehensible and variations in the answers were noted. However, some questions caused discomfort to the respondents, especially questions concerning priorities in relation to age and severity of illness. This was seen in their comments, such as, "this is not easy to answer”, “do I have to take a standpoint?”. This was further seen in the frequent use of the alternative “don’t know”, most often in relation to the questions about selecting between patients for a new hip joint $(40 \%, \mathrm{n}=22)$ and criteria for selection between patients needing coronary surgery (31\%, n=17). Men used the alternative “don’t know” more frequently than women did, 14 men (63\%) and 8 women (25\%) (Table 1). The respondents sometimes did not want to make a choice between different alternatives and showed that they wished to move on to the next question. The analysis also revealed that the respondents often reflected in relation to economic issues that were not included in the questionnaire. The impression from the interview situation and from the transcribed interviews was that the questions were clearly understood but that most respondents needed time to think about their answers. 


\section{Older people's standpoints in relation to priorities in health care}

Sixty-seven per cent $(n=36)$ of the older people did not want to favour any age group and stated that the same priority with respect to life-saving treatment should be given regardless of age (Table 1). Criteria such as “Being a family supporter” was favoured by $43 \%(n=23)$. The respondents also stated that the increasing health care costs should be financed by higher taxes $(62 \%, n=34)$ equally distributed between higher taxes in general and higher taxes on alcohol and tobacco. The question on self-inflicted disease showed that disease caused by alcohol or tobacco were not prioritised (Table 2), while injuries caused by football activity were prioritised by $38 \%(n=21)$ and problems caused by repeated abortions were prioritised by $26 \%(n=14)$. The respondents were unanimous in their opinion about who should make the decisions on priorities: $90 \%(n=49)$ wanted the doctor to be the decision maker.

\section{INSERT TABLE 1}

\section{INSERT TABLE 2}

The content analysis revealed two major areas in the narratives: the older people's experiences of prioritisation in health care and their reasoning about and view of prioritisation. In the latter area, different categories with internal variations seen as subcategories were identified, representing a variation in the view and reasoning.

\section{Experiences of prioritisation in health care}

Personal experiences of prioritisation in health care were rare among the older $(20 \%, n=11)$, and their experiences of health care in general were mostly stated to be positive. Six persons, who had experienced prioritisation themselves, considered it fair since they found it understandable that, for instance, people in work need cataract surgery before older people who have retired from work. The negative experiences of prioritisation $(n=5)$ all concerned someone else, a relative or a neighbour. The reason for the prioritisation in these cases was old age, which the respondents did not accept as a criterion.

\footnotetext{
“I have an acquaintance who is over 90. He’s been waiting for an operation but no ... he is too old so they're not going to operate. They quite simply told him to bear in mind that he is old. And it's not because he is too sick to be operated on. He had an operation for a hernia on one side, but when he came for an operation on the other side they told him to remember that he was old. And that hit him very hard. Other doctors have told him that it should be operated on.” (Woman, aged 81)
} 


\section{Reasoning about and views of prioritisation}

The respondents expressed worries about prioritisation, since the debate in the media made them aware of what the situation might be when they themselves might need health care. The prevailing view was that older people were put aside. In the older people's reasoning about prioritisation, they proceeded from themselves and their own situation. They turned to their own experience as a parent, a family supporter or as an older person, but also to the older population in general and their poor financial situation. They reflected over the fact that a person's position in their life span could make a difference in relation to the view of prioritisation. Several respondents pointed out that prioritisation was in conflict with the principle of human dignity, i.e. every human life is of equal value, and they described this conflict as a struggle between reasoning and feeling, i.e. what they thought was fair and what they felt emotionally.

The respondents' reasoning about and view of prioritisation could be described in four categories: Having to precede someone in rank (with internal variation seen as three subcategories), Prioritisation in relation to self-inflicted disease, View on decision makers in prioritisation and View of how to finance the increasing health care costs (Figure 1).

\section{INSERT FIGURE 1}

\section{Having to precede someone in rank}

The respondents' reasoning mostly showed an unwillingness to accept preceding someone in rank. The respondents who accepted preceding someone in rank primarily wanted to prioritise those who had greater needs, for example, people in pain and suffering and with lifethreatening conditions. When it came to prioritisation on the grounds of age, both younger and older people were in favour, and the respondents presented arguments for both groups: the younger people because of their role as family supporters and because they had an active life and the older because they have built the society and paid for their share. The reflections on age, however, raised questions about the demarcation line between young and old age. The respondents emphasised that age in itself is not as important as well-being. Having to precede someone in rank could be understood in the subcategories: Emphasis on all humans' equal value, Emphasis on the outcome of treatment, Emphasis on the scarce of resources in health care (Figure 1). 


\section{Emphasis on all humans' equal value}

The respondents showed an unwillingness to precede someone in rank and their statements were first and foremost based on the ethical principles of justice and human values. The older pointed out that all people in need of care should have the same right to health care and that it is a pity that it is necessary to make a choice between people. They also emphasised that younger persons should not be prioritised before older persons because of their activity in working life, since the older also have worked. They expressed fear that prioritisation would affect them negatively when they became in need of health care themselves. Another basis for the unwillingness to precede someone in rank was that thereby there was a risk that someone, for example in pain, could be put aside, and the perspective that no one should have to suffer was clearly stated.

\footnotetext{
"Everyone should have the care they need; it doesn't matter if they're young or old. I don't think it should be that only the younger ones get help because they work. We have paid taxes for many years to get health care and we should have it. We've done our bit once.” (Woman, aged 81)
}

\section{Emphasis on the outcome of treatment}

When reflecting on the difficulties in allowing one person to precede another, the respondents' varied between different ethical perspectives and values, especially regarding age and severity of disease. The respondents stated that there were several things that ought to be fulfilled when prioritisation had to be made: that the persons who needed treatment priority would be assured a dignified life, that the intervention should lead to maintaining the quality of life, that the prognosis should be positive and that the person needed to be motivated for treatment and toward their future life. The statements also contained views that if age is to be a criterion for prioritisation then it should be physical ageing and not chronological ageing. Even if a younger person may have a longer life ahead there was no reason why a 75-year-old man leading an active life should not have a knee replacement. "Growing old, is not the same as not wanting to live”, was a statement made by several respondents.

\footnotetext{
"Well, life-saving measures, that's something that can be discussed. If you think of the little ones that weigh 500 grams then you can question it. What kind of life do they save a person for? It's not just a matter of saving life, it has to be a life that's worth living. You can't just say that it's because it's young, you have to know what you're saving it for. My opinion is that you should save people for a dignified life.” (Woman, aged 66)
} 


\section{Emphasis on the scarce resources in health care}

When a view accepting to precede someone in rank was offered, it was based on the view that the health care resources really are scarce and if there were enough resources everyone should have the same right to health care. Another view was that there are so many older people and that they should not occupy the beds in hospitals at the expense of younger persons. The respondents stated that "if you are older and have had a good life, you are satisfied with that" The respondents also meant that younger persons, if they were working, could be prioritised before older persons and that older people now had their life behind them.

\footnotetext{
"I think that young people should go before the really old ones. My wife, for example, she's lying in the 'nursing home' and she's just not with it at all and that's no life to live when you don't know anything and don't recognise anyone and can't eat by yourself and all that. There's no meaning to that. I can understand that people have to set priorities when the money has run out.” (man, aged 78)
}

\section{Prioritisation in relation to self-inflicted diseases}

When reflecting in relation to the question of self-inflicted disease, the reason for the patients' problem was often elicited in order to get a background story i.e. whether the patient could blame him or herself. A few respondents stated that it is easier to take a stand if one can put a face on the person to be prioritised or has some relationship to that person. The standpoint that persons with self-inflicted diseases have themselves to blame was emphasised by several respondents. The question raised feelings of anger, but also compassion and the opinion that “it is not easy to change bad habits”. For instance, if the respondents were smokers themselves, it was easier to feel empathy for those persons with self-inflected diseases due to smoking. The respondents also would like to see some kind of guarantee for the chance of successful intervention, and that the intervention really would improve the person's situation.

“A football player can injure his new knee too. I think it's rather tricky, this. It's difficult.

A person who smokes knows what he's doing and a person who drinks lives his life after all. It’s all self-inflicted.” (Woman aged 66) 


\section{Views on decision makers in prioritisation}

The respondents emphasised that the decision makers were in a difficult situation and expressed compassion with them. The view that the health care personnel were best equipped to decide who should be prioritised was clearly stated. Neither local nor national politicians in health care were regarded as being able to set priorities in health care. Eleven respondents had comments about the politicians, for example that "they don't understand much" and the respondents expressed contempt for politicians in general and especially politicians in health care.

\footnotetext{
"No politicians at any rate, or the Board of Health, and not the general public either. It has to be doctors and nurses who make the decisions. If it's in a nursing home, for example, the nurses often know more than the doctors do. The general public can’t ... local health politicians can have..., you have to hope they have something in their heads.” (Woman aged 60)
}

\section{Views on how to finance the increasing health care costs}

The respondents were willing to pay for high quality in health care. But at the same time they said that the older in particular were not able to pay higher taxes, higher patient fees or private health care insurance. They also said that those who were to blame for their own condition could also pay for themselves. The overall view was that higher taxes were the fairest way to finance the increasing health care costs.

\footnotetext{
“It has to be paid for somehow. It'll have to be higher taxes, that's the only thing with equality in this context.” (Woman, aged 84).
}

\section{DISCUSSION}

The main reason for this pilot study was to investigate the applicability of an interview study to explore older people's experiences and views of prioritisation in health care. As the sample in this study was small (54 persons) the study needs to be replicated in a larger sample to establish valid and reliable results. However, the purpose of a pilot study is not so much to test research hypotheses but rather to test protocols, a data collection instrument, and other aspects of a study in preparation for a larger study (Polit \& Beck, 2004). 
When a structured interview is used it is of further importance to know whether the respondents understand the questions and directions or if they find any question in any way objectionable (Polit \& Beck, 2004). The analysis of respondents' reflections on the questions gave the impression that both the construction and content were well suited for the study group. Polit and Beck (2004) further suggested that one purpose of a pilot study can be to ask the participants their reactions to and overall impressions of the project and the respondents' discussion during the interview indicated that some aspects were missing. For example, it was not possible to know whether the respondents meant vertical (decisions between patients) or horizontal (decisions between i.e. disciplines) prioritisation when asked who should make decisions in prioritisation in health care. The respondents' reflections on the questions also revealed a need for questions directed toward economic areas, for example questions about whether people were willing to pay to avoid waiting lists. Some respondents showed through body language as well as through their moaning behaviour that it was difficult for them to respond to some of the questions; this was also visible in the frequent use of the alternative “don't know". The possibility to comment on and discuss their opinion with the interviewer seemed, however, to ease their discomfort. The procedure of distributing the questions in the form of a structured interview seems thus to be preferable when asking these kinds of delicate questions rather than through a postal survey.

Surprisingly few respondents reported having experienced prioritisation themselves. The reason for this could be either that the respondents have not been exposed to prioritisation or that prioritisation has not been made explicit. This implies that the result is mainly based on opinions and views rather than on experiences. Based on the judgement of the text quality, manifest content analysis was used (Berg, 2001). Although the interviews were cursory the result illuminated the view of prioritisation which were emphasised by the quantitative results. Credibility or believability was strengthen by having several researchers involved in the analysis process in an attempt to limit the risk of subjectively influence. Another aspect of credibility is to make the analysis visible for the reader (Graneheim \& Lundman, 2004) thus quotation from the original text was presented. Although several steps to increase the validity and reliability of the results have been taken, the text derived from the interviews was sparse and the results must be interpreted with caution.

The respondents emphasised that neither old nor young age groups should be prioritised in health care based on their belief that all people are of equal value. The quotation "growing old 
is not the same as not wanting to live" could be related to the principle of human dignity. The right to a decent minimum of health care could be represented by the words of an 80-year-old woman: "we have paid taxes for many years to get health care and we should have it".

According to $68 \%$ (37 persons) of the respondents people should have the same priority with respect to life-saving treatment, no matter what their age is. Different result was shown in an Australian study (Nord et al., 1995) where the same statement was chosen only by $42 \%$ of the respondents. The statement that people should have the same priority with respect to lifesaving treatment, unless they are very old was chosen by $41 \%$ of the Australian respondents while only 9\% (five respondents) in this study chose that alternative. In the Australian study the question about life-saving treatment was put to 551 persons, among whom only 25\% were over 60 years old. This could be an indication that older people's view on priorities in health care differs from the view of the younger population.

The principle of human dignity was also illuminated when the respondents highlighted aspects such as that the persons needed to be assured a dignified life if they were to have life saving treatment and that the treatment should lead to maintained quality of life, that the prognosis should be positive and that the person needed to be motivated for treatment and toward their future life. Other studies have also shown that the aspect of quality of life is an important outcome of treatment. For example, an American Health Services Commission was charged with developing a priority list of health care services, ranging from the most important to the least important for the entire population to be served (Hadorn, 1992). The results of the American study showed that estimates of how treatment affects quality of life were by far the single most important factor in determining the priority order on the list, which is in line with the results of this study. The value of the problems on the list was based on the results of a telephone survey of 1000 randomly selected Americans from one state, with no age reported. Further, the respondents were in favour of an 80-year-old healthy person when they had to choose between persons for a new hip joint. Only a few respondents wanted a 60-year-old with dementia to have the new hip joint. When reasoning, the respondents emphasised that if the resources were scare they could accept to precede someone in rank only to physical age but not to chronological age. On the other hand, the respondents also meant that younger persons, if they were working, could be prioritised before older persons. This indicates that the principle of need and solidarity were seen as subordinated the cost-efficiency principle which is in contrast to what the Swedish Parliamentary Priority Commission recommends (SOU, 1995). Thus, the respondents seemingly estimated how treatment would affect quality 
of life, regardless of age but considering the individuals' initial physical and mental condition. There is thus reason to believe that the outcome related to quality of life is an important factor to consider when it comes to prioritisation in health care and there is also a reason to believe that this view is not influenced by age.

When it came to choosing between persons, with self-inflicted disease, smokers and alcoholics were given the lowest priority. Prioritisation in relation to self-inflicted disease should, according to the participants, be based on some guarantee of the chance of a successful intervention. It is known from the literature, for example Bowling (1996), that the public seems to support the view that people with self-inflicted conditions in general should receive lower priority for care. Beauchamp \& Childress (2001) stated that lifestyle itself may be medically relevant in predicting the probability of a successful transplantation. A patient's heavy use of alcohol may reduce the probability that a liver transplant will be successful, and neither medicine nor justice requires that such a patient receive a transplant in conditions of scarcity (Beauchamp \& Childress, 2001). This is a question that needs to be discussed and illuminated more in all age groups, especially since disease caused by lifestyle seem to be increasing among certain groups in the society (2001). This may also involve lifestyles not only connected to alcohol and smoking habits, but also involving excessive use of e.g. food or exercise.

\section{Conclusions and further research}

With regard to the result of the study the questions used covered relevant areas, revealed variations in the answers and seemed suitable for the study group. However, the questionnaire needs to be supplemented with additional questions concerning, among other things, health economics. The ethical theoretical frame upon which the questions were based could be reflected in the answers from the respondents, which strengthened the validity of the questions. The validity was also strengthen by the similar results found in both qualitative and quantitative analysis. The procedure with tape-recorded structured interviews appears to be a suitable way to collect data as complementary nuances to the respondents' answers were captured. There is a need for further research, developing knowledge about older people’s views of both prioritisation and of how to finance the increasing health care costs, especially as they are at risk of becoming a target when resources are scarce and as they are often in a worse situation economically than the younger population. This pilot study indicated that older people's experiences of prioritisation in health care are rare and that their view of prioritisation differs from the view of younger people. There is further reason to believe that 
the outcome of treatment related to quality of life is an important factor to consider when it comes to prioritisation in health care and that this view is not influenced by age. 


\section{ACKNOWLEDGEMENTS}

We are most grateful to the older persons for their participation in this study. We are also grateful to Alan Crozier and Geoff Dykes for revision the language, The Vardal Foundation for Health Care Sciences and Allergy Research, the Capio Research Foundation and to the Swedish Council for Working Life and Social Research for financial support.

The Swedish National study on Aging and Care, SNAC, (www.snac.org) is initiated and financially supported by the Ministry of Health and Social Affairs, Sweden in collaboration with the participating County Councils, Municipalities and University Departments. It is a longitudinal study in two parts: a population study with a comprehensive data collection including people from 60 to 96 years of age and a study of health care and social services offered to people of 65 years of age and over. It has four bases; Kungsholmen, Stockholm; Nordanstig, in the County of Gävleborg; Karlskrona, in the county of Blekinge and the Region of Skåne and five of the municipalities there, Eslöv, Hässleholm, Osby, Malmö and Ystad. We are grateful to the participating counties and municipalities and also to the Stockholm Gerontology Research Centre, The Geriatric Development Centre at Malmö University Hospital, The Blekinge Institute for Research and Development, Psychiatry and Primary care, Lund University, Departments of Nursing and Community Medicine. 


\section{REFERENCES}

Beauchamp, T. L. \& Childress, J. F. (2001) Principles of biomedical ethics, Oxford University Press, New York.

Bell, N. K. (1989) What setting limits may mean: a feminist critique of Daniel Callahan's Setting Limits. Hypatia, 4, 169-78.

Berg, B. L. (2001) Qualitative research methods for social sciences, Allyn \& Bacon, USA.

Bowling, A. (1996) Health care rationing: the public's debate. BMJ, 312, 670-4.

Burns, N. \& Grove, S. K. (2001) The Practice of Nursing Research Conduct, Critique, and Utilization, WB Saunders Company, Philadelphia.

Calltorp, J. (1999) Priority setting in health policy in Sweden and a comparison with Norway. Health Policy, 50, 1-22.

Graneheim, U. H. \& Lundman, B. (2004) Qualitative content analysis in nursing research: concepts, procedures and measures to achieve trustworthiness. Nurse Education Today, 24, 105-12.

Hadorn, D. C. (1992) The problem of discrimination in health care priority setting. JAMA, 268, $1454-9$.

Ham, C. (1997) Priority setting in health care: learning from international experience. Health Policy, 42, 49-66.

James, M. (1999) Towards an integrated needs and outcome framework. Health Policy, 46, 165-77.

Johannesson, M. \& Johansson, P. O. (1996) The economics of ageing: on the attitude of Swedish people to the distribution of health care resources between the young and the old. Health Policy, 37, 153-61.

Jordan, J., Dowswell, T., Harrison, S., Lilford, R. J. \& Mort, M. (1998) Health needs assessment. Whose priorities? Listening to users and the public. BMJ, 316, 1668-70.

Kinnunen, J., Lammintakanen, J., Myllykangas, M., Ryynanen, O. P. \& Takala, J. (1998) Health care priorities as a problem of local resource allocation. International Journal of Health Planning and Management, 13, 216-29.

Lagergren, M., Fratiglioni, L., Hallberg, I., Berglund, J., Elmståhl, S., Hagberg, B., Holst, G., Rennemark, M., Sjölund, B.-M., Thorslund, M., Wimo, A. \& Winblad, B. (2004) A longitudinal study with integrated population and care service data - The Swedish National study on Ageing and Care (SNAC). Aging Clinical and Experimental Research.

Lewis, D. M. \& Cuevas, N. M. (1996) Validity and reliability issues in published public health and social policy research. Journal of Health and Social Policy, 8, 23-38.

Mossialos, E. \& King, D. (1999) Citizens and rationing: analysis of a European survey. Health Policy, 49, 75-135.

Myllykangas, M., Ryynanen, O. P., Kinnunen, J. \& Takala, J. (1996) Comparison of doctors', nurses', politicians' and public attitudes to health care priorities. Journal of Health Services Research and Policy, 1, 212-6.

Myllykangas, M., Ryynanen, O. P., Kinnunen, J. \& Takala, J. (1997) Attitudes to cuts in expenditure and increased fees in health care. Public Health, 111, 71-5.

Nord, E., Richardson, J., Street, A., Kuhse, H. \& Singer, P. (1995) Maximizing health benefits vs egalitarianism: an Australian survey of health issues. Social Science and Medicine, 41, 1429-37.

Nord, E., Street, A., Richardson, J., Kuhse, H. \& Singer, P. (1996) The significance of age and duration of effect in social evaluation of health care. Health Care Analysis, 4, 10311.

Polit, D. F. \& Beck, C. T. (2004) Nursing Research Principles and Methods, Lippincott, Philadelphia. 
Ryynanen, O. P., Myllykangas, M., Kinnunen, J., Halonen, P. \& Takala, J. (2000)

Prioritization attitudes among doctors and nurses examined by a scenario method. International Journal of Technology Assessment in Health Care, 16, 92-9.

Ryynanen, O. P., Myllykangas, M., Kinnunen, J. \& Takala, J. (1997) Doctors' willingness to refer elderly patients for elective surgery. Fam Pract, 14, 216-9.

Ryynanen, O. P., Myllykangas, M., Kinnunen, J. \& Takala, J. (1999) Attitudes to health care prioritisation methods and criteria among nurses, doctors, politicians and the general public. Social Science and Medicine, 49, 1529-39.

SCB (Ed.) (2003) Statistical Yearbook of Sweden 2002, Statistiska Centralbyrån, Stockholm.

Socialstyrelsen (2001) Health in Sweden - Sweden's Public Health Report, Socialstyrelsen, Stockholm.

SOU (1995) Priorities in health care. Ethics, economy, implementation. Final report by The Swedish Parliamentary Priorities Commission. (Vårdens svåra val), Socialdepartementet, Stockholm.

WHO (2000) Social Development and Ageing, Crisis or Opportunity, World Health Organization, Geneva.

Zweibel, N. R., Cassel, C. K. \& Karrison, T. (1993) Public attitudes about the use of chronological age as a criterion for allocating health care resources. Gerontologist, 33, 74-80. 
Table 1. Priority settings; questions with one choice, and older persons' responses, $n=54$, men and women

\begin{tabular}{|c|c|c|c|c|}
\hline \multirow[t]{2}{*}{ Questions } & \multirow[t]{2}{*}{ Alternatives } & \multicolumn{3}{|c|}{ Response } \\
\hline & & $\mathbf{n}$ & $(\%)$ & $\mathbf{m} / \mathbf{w}$ \\
\hline \multicolumn{5}{|l|}{ 2. Who do you think should be prioritised in health care? } \\
\hline & Younger patients & 8 & $(15)$ & $3 / 5$ \\
\hline & Older patients & 6 & (11) & $5 / 1$ \\
\hline & All age groups & 36 & (67) & $14 / 22$ \\
\hline & Don’t know & 4 & (7) & 14 \\
\hline \multirow{5}{*}{$\begin{array}{l}\text { 3. What alternative do you think is most fair? } \\
\text { (from Nord et al 1996) }\end{array}$} & & & & \\
\hline & $\begin{array}{l}\text { Among people with life-threatening illness, younger patients should have some } \\
\text { priority over older people }\end{array}$ & 9 & $(17)$ & $3 / 6$ \\
\hline & $\begin{array}{l}\text { People should have the same priority with respect to life-saving treatment, } \\
\text { unless they are very old }\end{array}$ & 5 & (9) & $3 / 2$ \\
\hline & $\begin{array}{l}\text { People should have the same priority with respect to life-saving treatment, no } \\
\text { matter what their age is }\end{array}$ & 37 & (68) & $16 / 21$ \\
\hline & Don't know & 3 & (6) & $/ 3$ \\
\hline \multicolumn{5}{|l|}{ 4. Who should be the one to have a new hip joint? } \\
\hline & A 60-year-old with dementia & 2 & $(4)$ & 2/ \\
\hline & A 70-year-old with coronary disease & 9 & $(17)$ & $2 / 7$ \\
\hline & An 80-year-old healthy person & 21 & (39) & $4 / 17$ \\
\hline & Don’t know & 22 & $(40)$ & $14 / 8$ \\
\hline \multicolumn{5}{|l|}{$\begin{array}{l}\text { 7. What method or which criteria ought to be used when } \\
\text { choosing between patients who should be satisfactorily } \\
\text { treated? }\end{array}$} \\
\hline \multirow[t]{6}{*}{ (from Mossialos \& King, 1999) } & Lottery & - & - & - \\
\hline & The patient's importance in society & 2 & $(4)$ & 2/ \\
\hline & The patient's age & 12 & $(22)$ & $1 / 11$ \\
\hline & The patient's possibility to pay & - & - & - \\
\hline & The patient's importance in family support & 23 & (43) & $10 / 13$ \\
\hline & Don’t know & 17 & (31) & $9 / 8$ \\
\hline \multirow[t]{6}{*}{$\begin{array}{l}\text { 8. How should the increasing health care costs be financed? } \\
\text { (from Mossialos \& King, 1999) }\end{array}$} & Higher taxes in general & 17 & (31) & $10 / 7$ \\
\hline & Higher taxes on alcohol and tobacco & 17 & (31) & $5 / 12$ \\
\hline & Reduction of social expenses & 3 & (6) & $1 / 2$ \\
\hline & Higher patient fees & 1 & $(2)$ & $1 / 1$ \\
\hline & Private health insurance & 1 & (2) & $1 / 1$ \\
\hline & Don't know & 15 & $(28)$ & $6 / 9$ \\
\hline
\end{tabular}


Table 2. Priority setting; questions with alternatives to order in precedence and older persons' responses ( $\mathrm{n}=54)$

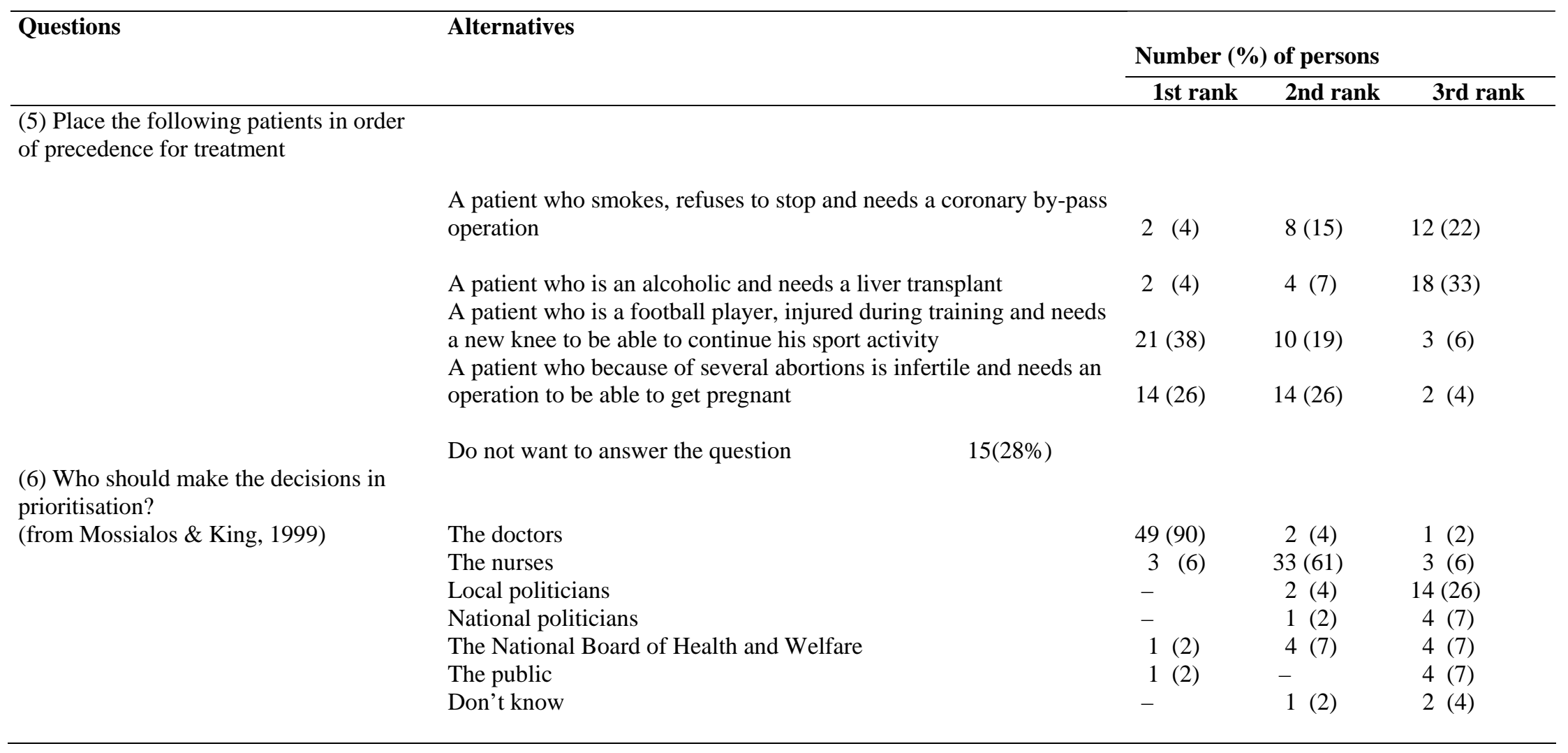


Having to precede someone in rank

Emphasis on all humans' equal value

Emphasis on the outcome of treatment

Emphasis on the scarce resources in health care

Prioritisation in relation to self-inflicted diseases

View on decision makers in prioritisation

View of how to finance the increasing health care costs

Figure 1. Older people's reasoning about and view of prioritisation. 